\title{
Mortalidade e migração no período da seca de 1877-1879 na freguesia de São José (Fortaleza/CE)
}

\author{
Mortality and migration in the drought period from 1877 to 1879 in the \\ parish of São José (Fortaleza/CE)
}

\section{Dayane Julia Carvalho Dias*}

\section{Resumo}

No período de 1877 a 1879, a província do Ceará foi atingida pelo fenômeno climático da seca, a qual ocasionou grandes repercussões sociais, culturais e econômicas. Tal fenômeno interferiu no funcionamento da dinâmica populacional da região, sobretudo na alteração de perfis migratórios e de mortalidade. Desta forma, este artigo tem por objetivo analisar o impacto causado pela seca na dinâmica populacional da freguesia de São José (Fortaleza), com base em fontes históricas - os registros paroquiais de óbitos. Por meio de tais fontes, são analisados aspectos relacionados ao sexo, idade, naturalidade e causa de óbito. Os resultados indicam um aumento da mortalidade no ano de 1878 , devido à presença de retirantes na Capital (Fortaleza) e à disseminação de doenças epidêmicas.

Palavras-chave: Seca; Mortalidade; Migração; Fortaleza; Ceará.

\section{Abstract}

Between 1877 and 1879, the Province of Ceará was affected by the drought climatic phenomenon, which caused great social, cultural and economic repercussions. This phenomenon interfered with the functioning of the region's population dynamics, especially with the alteration of migration and mortality profiles. Thus, this article aims to analyze the impact caused by drought on population dynamics in the parish of São José (Fortaleza), based on historical sources - the parish records of deaths. Through these sources, aspects related to sex, age, birthplace, and cause of death are analyzed. The results indicate an increase in mortality records in the year 1878, due to the presence of retreatants in the Capital (Fortaleza) and the spread of epidemic diseases.

Keywords: Drought; Mortality; Migration; Fortaleza; Ceará.

\footnotetext{
*Doutoŕanda em Demografia pela Universidade Estadual de Campinas.E-mail: dayanejuliacd@gmail.com
} 


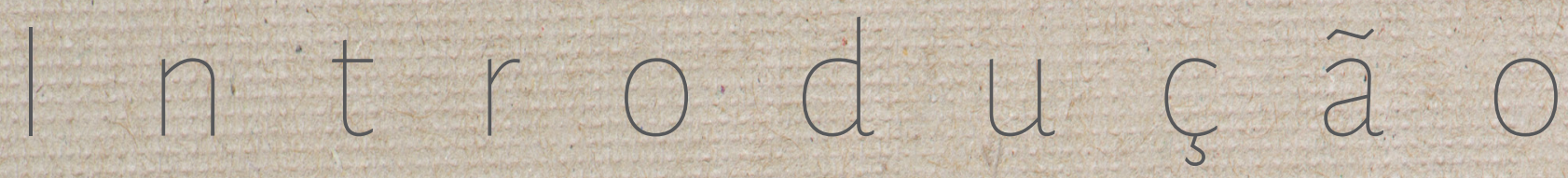

- longo de todo o século XIX, a província do Ceará foi atingida por diversas secas que se distribuíram entre os anos de 1804, 1809, 1816-1817, 1824-1825, 1830, 1844-1845 (VIEIRA JUNIOR, 2002), 1877-1879 e 1888-1889. Dentre estas, a seca mais destruidora ocorreu entre 1877 e 1879 em todas as províncias do Norte (ROCHA POMBO, 1922) ${ }^{1}$. Na província do Ceará o impacto foi mais forte, o que pode ser verificado pelo expressivo volume de óbitos registrados e pelos movimentos migratórios. Mais do que um fenômeno natural, o desastre teve consequências sociais, econômicas e culturais, uma vez que alteraram as relações das pessoas com as migrações e a morte.

Nesta perspectiva, o objetivo deste artigo é analisar o impacto causado pela seca na dinâmica populacional da freguesia de São José da Catedral2 (região central de Fortaleza, Ceará), no período de 1877 a 1879, com foco nos componentes da mortalidade e da migração 3 . Para concretizar o estudo, são utilizadas fontes históricas compostas pelos registros paroquiais de óbitos dessa freguesia durante o período. As principais categorias de análise são: o sexo, a idade, a causa de óbito e a naturalidade. As informações por sexo e idade permitem identificar o diferencial de mortalidade entre homens e mulheres, bem como os grupos etários mais atingidos pela alta mortalidade. Por meio dos registros das causas de óbito, é possível traçar um perfil das doenças que mais atingiram a população. Paralelamente, com base nas informações sobre a naturalidade, pode-se também analisar a presença de imigrantes em Fortaleza e demarcar as regiões que mais enviaram retirantes para a Capital cearense.

Entre 1870 e 1879, na paróquia de São José (Fortaleza), foram registrados 20.748 óbitos. Dentre eles, 79,8\% (16.557) ocorreram no período da seca de 1877-1879. Diante deste aumento catastrófico da mortalidade nesse período, surgiu a inquietude de descobrir quem eram essas pessoas e de onde vieram. Não se trata apenas dos números, e sim de subsídios para compreender o impacto social, cultural e econômico por trás dessas cifras. Para tanto; procura-se entender: 1) entre homens,

1 expressão províncias do Norte, região posteriormente denominada Nordeste, inclui: Ceará, Rio Grande do Norte, Maranhão, Piauí, Paraíba, Pernambuco, Alagoas, Sergipe è Bahia (MELO, 1984).

2 Segundo o Recenseamento Imperial de 1872, a população de Fortaleza (Capital do Ceará) era composta pelas freguesias de São José (região central de Fortaleza), Nossa Senhora da Conceição de Mecejana e Nossa Senhora dos Prazeres de Soure. 30 conceito de migração abordado neste artigo diz respeito à migração interna, dentro da província do Ceará, caracterizada pelo movimento de entrada de pessoas (imigração) na cidade de Fortaleza - os chamados retirantes da seca. 
mulheres, crianças, jovens, adultos e idosos, quem foram os mais impactados pela alta mortalidade?:) morreram de quê? e 3) de onde vieram? Tais questionamentos permitirão compreender a dinâmica migratória e de mortalidade, não como resultado inerente à catástrofe da seca, mas como processos históricos que tiveram as pessoas comuns como os sujeitos envolvidos.

Os registros paroquiais de óbitos utilizados estão disponíveis online no sítio Family Search4. Foram transferidas da fonte primária para uma base de dados, na forma de planilha online do Excel, as informações relacionadas a: data do óbito, sexo, idade, cor/etnia, legitimidade, estado civil, condição jurídica, naturalidade, causa de óbito e local de sepultamento. A manipulação dos dados e a vinculação entre as variáveis foram realizadas por meio da utilização do software estatístico SPSS (Statistical Package of the Social Sciences).

Os aportes teóricos que fundamentam esta pesquisa são, antes de tudo, interdisciplinares. Embora o principal objetivo seja realizar uma análise pelo viés da Demografia Histórica e/ou História da População, também será contemplada a análise voltada para a História Social e Cultural, na medida em que se busca relacionar as dinâmicas dos deslocamentos populacionais e da mortalidade, nesse período histórico da seca no Nordeste, considerando a importância da atuação de sujeitos históricos envolvidos intimamente nesse processo. A relação entre a Demografia Histórica e a História Social e Cultural são estreitas, visto que são frutos de uma nova concepção de pensar e escrever a história: a Nova Histórias.

O desenvolvimento de estudos de Demografia Histórica, por meio do uso das estatísticas vitais de nascimento, casamento e morte são a chave para o entendimento de aspectos relacionados a classe, cultura e consciência de uma sociedade (PORTER, 2011, p. 300). Diante disto, se comparados a outras fontes históricas escritas, os registros paroquiais se destacam por ser um tipo de fonte com característica universal, ao incorporar todos os segmentos populacionais - livres, escravizados e libertos. Tais registros contêm informações importantes sobre a história social e cultural das populações, sob o domínio do catolicismo imposto pelo Império Português, tal como afirma Marćlio (2004, p. 15):

Cito esses detalhes para que se possa perceber, desde logo, a riqueza de informações contidas nesses documentos de primeira ordem, para a reconstrução da história social e cultural das populações católicas e a potencialidade de explorações que permitem, para desvendar o passado em várias direções. Pobres.e ricos, plebeus e nobres, brancos, negros e índios, homens e mulheres, todos sem exceção, quando batizados, casados ou falecidos tinham esses fatos vitais registrados em livros especiais, que eram conservados pela Igreja.

4 IGREJA CATÓLICA. Registros paroquiais, 1726-1952. São José da Catedral (Centro, Fortaleza, Ceará). Óbitos 1862-1873, 1872$1882,1873-1880,1878-1889$.

5 Segundo Burke (2011, p. 12), a base filosófica da Nova História é a ideia de que a realidade é social ou culturalmente constituída. 
No entanto, o fato de representar somente a população católica constitui uma limitação da fonte, visto que excluía parte da população: os protestantes, presentes no território brasileiro desde o Segundo Reinado; a população de indígenas não aldeados; e os africanos ainda não batizados (MARCÍLIO, 2004, p. 16). A colonização portuguesa impôs a religião católica a grupos étnicos que já tinham suas crenças e culturas bem definidas, comoé o caso dos indígenas, que, quando não foram exterminados, foram aldeados. Similarmente, os africanos foram submetidos ao tráfico ultramarino para serem escravizados em outros continentes e a uma nova religião, por meio do batismo.

Apesar das limitações, os registros paroquiais são fontes importantes para estudos históricos, sociais e culturais do nosso passado colonial e imperial. No caso dos registros de óbitos, podem ser úteis para o estudo de padrões de mortalidade e condições de vida de populações pretéritas. Nesse sentido, com foco na compreensão do contexto histórico, social e cultural, os próximos itens serão dedicados à questão da presença de imigrantes da seca na capital do Ceará, bem como às epidemias e medidas sanitárias adotadas.

\section{Imigrantes na Capital: os retirantes da seca de 1877-1879}

A seca ocorrida entre 1877 e 1879 nas províncias do Norte estimulou a imigração massiva de indivíduos oriundos do interior em direção às capitais provinciais, em busca de socorros públicos. Tais imigrantes eram denominados "retirantes da seca": Nas regiões do Sertão Cearense, onde a economia era baseada, principalmente, na pecuária e na agricultura, o impacto dà seca foi maior, causando fome, morte e deslocamento. As migrações eram uma estratégia de sobrevivência, em decorrência da falta de água e de alimentos (VIEIRA JUNIOR, 2002). No Ceará, o impacto da seca foi tão forte que a província recebeu recursos de províncias vizinhas, as quais também passavam pelo mesmo processo, como é o caso da província de Pernambuco, que "remeteu em 6 de abril de 1877 uma quantia de 464\$000 para as vítimas da seca pela comissão acadêmica do Recife" (TEÓFILO, 1922, p. 84).

No interior do Ceará, havia se difundido entre a população o boato de que o "rei tinha mandado muita comida e roupa (para a capital) para se distribuírem com a pobreza" (TEÓFILO, 1922 , p. 97). Em 1877, primeiro ano da seca, o governo provincial ainda remetia socorros públicos, principalmente na forma de gêneros alimentícios, para a população do interior da província. Contudo, conforme o tempo foi passando, aumentou a dificuldade da distribuição dos gêneros entre as localidades mais distantes do litoral. Segundo o relatório apresentado pelo presidente da província, João Aguiar, o transporte dependia exclusivamente de animais de carga, mas, 
em função da seca, não era garantida a alimentação desses animais durante a viagem, acrescentando-se a isso o risco de saques (ACUIAR, 1878, p. 10). Logo se difundiu, entre os habitantes de áreas mais atingidas pela seca, a notícia de que o governo distribuía recursos apenas para a população da área litorânea. Diante disto, os retirantes migraram, frequentemente em grupos, rumo ao litoral, conforme atesta o relatório de José Barros, apresentado à Assembleia Legislativa Provincial, no dia 1 de novembro de 1878: "A população faminta, semi-nua, desvairada, precipitava-se do centro para o littoral, como uma torrente, alastrando de cadavares as estradas; porque chegara a todos os pontos a noticia de que, por falta de transporte, somente se distribuirião socorros nas cidades próximas do mar" (BARROS, 1879, p. 39).

Dentre as províncias do Norte, a Capital do Ceará foi a cidade que mais recebeu imigração de retirantes 6 . Em 1878, havia em Fortaleza cerca de 100 mil retirantes, para uma população residente, à época, em torno de 30 mil habitantes (PONTE, 1999, p. 84). Teófilo (1922) apresenta um número diferente de retirantes, aproximadamente 60.000. Apesar de divergentes, essas cifras são indícios da forte presença de imigrantes, vítimas da seca, na Capital. Grande parte desse movimento pode ser entendida por conta da ideia, construída no imaginário popular, de que na Capital da província havia dinheiro e trabalho para os retirantes com recursos, vindos da Corte imperial. Dessa forma, Fortaleza foi retratada como uma espécie de "Terra Prometida", conforme relatado na historiografia regional: "Animados com esta esperança, diariamente partiam, de todos os pontos, inúmeras caravanas em procura da Terra Prometida" (TEÓFILO, 1922, p. 97).

A presença da grande massa de migrantes, retirantes da seca, na Capital logo se tornou um problema de saúde e higiene pública. Os retirantes eram considerados, pelas autoridades provinciais e pela elite local, portadores de doenças e causadores da desordem urbana. A presença de "flagelados, esfarrapados, famintos, sujos e doentes" causou horror entre a classe dominante na cidade de Fortaleza (SECRETO, 2003, p. 3). Com a aglomeração de retirantes em Fortaleza, o Governo Provincial do Ceará, comapoio do Coverno Imperial, agiu em duas frentes para a resolução do problema: 1) o encaminhamento dos retirantes para o trabalho, por meio do projeto Pompeu Sinimbú; e 2) o estímulo à emigração subsidiada pelo Estado para outras regiões do País?.

6 No Ceará, além de Fortaleza, outras cidades também foram receptoras de imigrantes vítimas da seca: Maranguape, Baturité, Aracaty e as vilas de Pacatuba e Mecejana, além da povoação de Arronches (TEÓFILO, 1922, p. 111). Acrescenta-se, ainda, a Vila do Crato, que tinha maior resistência à seca, devido ao grande número de nascentes de água (VIEIRA JUNIOR, 2002).

7. Em consequência dessa seca, o Ceará presenciou um significativo crescimento da emigração: A Amazônia e as províncias do Sul foram os principais destinos dos cearenses. Amazônia por ter sido um local atrativo, devido às oportunidades de trabalho geradas pela produção da borracha (CARDOSO, 2014; TEÓFILO, 1922). Calcula-se que, entre 1869 e 1900, 300.902 pessoas deixaram o Ceará. Destas, 255.526 (85\%) foram para a Amazônia e 45.376 (15\%) para as províncias do Sul do Brasil (GIRÃO, 1947). As secas paralisavam a economia rural, dificultando o abastecimento das cidades e do campo, o que provocava fome e desemprego entre a população, aumentando os riscos de epidemias e a frequência de mortes. Diante desse contexto econômico-demográfico, muitas pessoas migraram para outras regiões do Brasil, em busca de oportunidades de trabalho e possibilidades de acesso ou posse da terra (NOZOE; BASSANEZI; SAMARA, 2003). 
Por lei, o governo provincial era obrigado a fornecer socorros a esses retirantes. No entanto, as comissões de socorros públicos, além da distribuição de alimentos e remédios, encaminhavam os retirantes para o trabalho, como forma de tirar proveito da situação (CARDOSO, 2014; SOUZA, 2015). Para isso, foi aprovado o projeto Pompeu Sinimbú, proposto pelo senador Tomás Pompeu de Souza Brasil e implantado em 1878. O projeto consistia em conceder auxílio do governo ao retirante, desde que ele se dispusesse a realizar obras públicas. Era uma forma de promover o progresso material da província, por meio da construção e reforma de pontes, estradas, prédios públicos, praças, escolas, cemitérios, igrejas, e de contornar o problema das estiagens, com a construção de açudes (SOUZA, 2015). Desta forma, o aproveitamento da mão de obra dos retirantes também foi uma estratégia das autoridades provinciais para evitar a desordem pública, diante da ameaça que eles representavam nas cidades.

Apesar de todo esse discurso que associava os retirantes às doenças e à desordem, a seca ocorrida entre 1877 e 1879 e a consequente aglomeração de retirantes nas capitais, decorrente da migração/mobilidade mais intensa, não foram os verdadeiros motivos para a disseminação das doenças infecciosas ${ }^{8}$. Dentre as doenças epidêmicas predominantes durante o período, destacam-se a febre amarela e a cólera, que surgiram no Brasil a partir de 1850 e afetaram diversas províncias. No Ceará, as secas pioraram a situação, ao aumentar os riscos de epidemias e a frequência de mortes por essas doenças e outras causas. Diante disso, uma série de medidas sanitárias foram implementadas, conforme será discutido no próximo item.

\section{Doenças epidêmicas e medidas sanitárias}

O impacto causado pelas doenças epidêmicas gerou abertura e incentivo para a implantação de políticas destinadas à melhoria da saúde pública no Brasil do século XIX. Não somente no Ceará, mas em todo o Brasil, a partir de 1850, foram implantadas medidas de intervenção para a manutenção da salubridade pública e limpeza, devido ao aparecimento das epidemias de cólera, febre amarela e varíola (CHALHOUB, 1996; COSTA, 1979; WITTER, 2007). Em Fortale$\mathrm{za}$, a varíola se manifestou de forma mais intensa a partir de setembro 1878 , em decorrência também da grande seca que atingiu a região. A febre amarela apareceu em 1851 e a cólera em 1862 (BARBOSA, 2009; TEÓFILO, 1922). Todas as medidas que visavam à limpeza pública

8 Doenças infecciosas são definidas como doenças causadas por micro-organismos, como vírus, bactérias, protozoários ou fungos. Doenças contagiosas são transmissíveis, por contato direto ou indireto com pessoas infectadas. As doenças infecciosas também podem ser transmitidas de pessoa para pessoa, sendo denominadas infectocontagiosas 
fazem parte do arsenal do pensamento higienista do Oitocentos, na forma de atitudes normativas e repressivas. A ideologia higienista tinha por objetivo incentivar a substituição de velhos hábitos, considerados incivilizados, por novos hábitos, vistos como sinônimo de civilização (COSTA, 1979).

Em períodos de seca, a situação agravava-se (BARBOSA, 2009). Desde a seca de 1844-1845, as políticas públicas colocadas em prática para enfrentar os períodos de estiagens eram idealizadas não somente em nível provincial, mas atendiam às recomendações provenientes diretamente da Corte. As medidas eram de caráter preventivo, como a construção de açudes, a avaliação das condições das lagoas, riachos e córregos, assim como da qualidade do abastecimento de água. Entretanto, também foram implementadas medidas emergenciais, em momentos de surtos epidêmicos, como a criação das "Comissões Sanitárias", para o fornecimento de remédios e gêneros alimentícios, e o envio de médicos para as localidades atingidas por alguma doença (BARBOSA, 2009; CARDOSO, 2014).

Entre 1850 e 1860, em virtude do crescimento econômico possibilitado pela exportação do algodão do Ceará e, sobretudo, devido ao impacto causado pelas doenças e ao aumento da população no núcleo urbano, intervenções sanitárias foram iniciadas na Capital. O processo de remodelação e aformoseamento da cidade começou com intervenções e reformas sanitárias. Durante esse período, Fortaleza havia se tornado o principal centro político, social, comercial e financeiro do Ceará (PONTE, 1999, p. 75). Foram construídos hospitais, como a Santa Casa de Misericórdia (1861) e o Lazareto da Lagoa Funda (1857). Este último, mais afastado da área urbana, era destinado ao tratamento de vítimas de doenças infecciosas e contagiosas, principalmente a varíola (PONTE, 1999, p. 77).

Em 1866, o cemitério São Casimiro, então localizado na área urbana central de Fortaleza, foi transferido para longe da cidade, com um novo nome: cemitério São João Batista (PONTE, 1999, p. 80). Tal cemitério é o local de sepultamento que aparece nos registros paroquiais de óbitos aqui discutidos, embora o cemitério de Lagoa Funda também apareça, sobretudo, pelo enterramento das vítimas provocadas pela varíola.

Neste período, a prática de isolamento de doentes e de construção ou transferência de edifícios públicos para áreas distantes do núcleo urbano foi comum no Brasil e no mundo. Alguns médicos sanitaristas à época acreditavam que as doenças infecciosas teriam origem nos miasmas?. Dessa forma, os matadouros, mercados, hospitais, lazaretos e cemitérios foram construídos ou transferidos para locais afastados do núcleo urbano (JORGE, 2007).

9. A teoria biológica miasmática, formulada por Thomas Sydenham e Giovanni Maria durante o século XVII, afirmava que o contágio das doenças acontecia por meio da inalação de miasmas, caracterizados por odores fétidos provenientes de matéria orgânicá em putrefação nos solos e lençóis freáticos contaminados. 
Nessa perspectiva, a disseminação das doenças infecciosas na forma de epidemias exigiu do Estado imperial e provincial um posicionamento para o combate a essas doenças. Em nível provincial, este cenário propiciou a adoção de medidas sanitárias para manter a salubridade e a higienização, principalmente nos núcleos urbanos. Além da limpeza das ruas e fontes de água, as medidas também se traduziram na construção de obras públicas, como hospitais, cemitérios e matadouros, entre outras.

No próximo item, com base nos registros de óbitos, pretende-se apresentar dados concretos sobre os níveis de mortalidade, que fornecem subsídios para analisar o impacto causado pela seca e pelas doenças no conjunto da população.

\section{A seca de 1877-1879 nos registros paroquiais de óbitos}

Segundo o Recenseamento Geral do Império de 1872, a província do Ceará tinha uma população de 721.686 habitantes. Em 1890, a população cresceu para 805.687. A paróquia de São José, região central da cidade de Fortaleza, tinha uma população de 21.372 habitantes em 1872, e foi para 23.465 em 1890 . Estes números podem ser mais bem compreendidos quando analisados por taxas de crescimento médio anual da população. A taxa de crescimento geométrico representa o percentual de crescimento médio anual da população (RIPSA, 2008, p. 62). Neste caso, indica o ritmo de crescimento populacional entre dois períodos, correspondentes aos censos demográficos de 1872 e $1890^{10}$, intervalo durante o qual o Ceará cresceu a uma taxa média anual de 0,61\%, enquanto Fortaleza, à 0,52\%. Embora a taxa de crescimento geométrico entre os dois recenseamentos tenha sido positiva, o crescimento registrado foi muito baixo, indicando que, no período de 18 anos, a população praticamente não registrou crescimento.

A explicação para essa cifra de população de 1890 tem origens na seca de 1877-1879. Teófilo (1922, p. 229) afirma: "segundo o recenciamento procedido em 30 de setembro (1878), havia uma população de 114.404 pessoas; e quarenta dias depois, em outubro, 0 arrolamento apresentava a cifra de 108.656 , havendo um decrescimento de 5.784 !". Os dados trazidos pelo autor devem ser analisados à luz do contexto e com senso crítico. É preciso considerar

100 indicador é fortemente influenciado pela dinâmica da mortalidade, da natalidade e das migrações. Pode ser útil para analisar variações geográficas de crescimento populacional (RIPSA, 2008, p. 62). 
o quantitativo de retirantes que aumentou a população residente da cidade, a qual variou entre 60.000 e 100.000 retirantes (PONTE, 1999; TEÓFILO, 1922).

Nesse sentido, a população de Fortaleza não apresentou alto crescimento vegetativo entre 1872 e 1890 devido aos efeitos que a seca de 1877-1879 ocasionou na dinâmica populacional, não apenas por aumentar a mortalidade, como também por impulsionar a emigração para outras regiões do País. Assim, é consenso que a seca de 1877-1879 foi uma das mais desastrosas, ocasionando grande mortalidade e estimulando a migração de parte da população para outras regiões do Império brasileiro (PONTE, 1999; SECRETO, 2003; TEÓFILO, 1922). Entretanto, esse impacto nunca foi analisado com base nos registros paroquiais, considerando os quesitos idade, sexo, causa de óbito e naturalidade.

No período analisado (1870 a 1879), a freguesia de São José da Fortaleza apresentou um total de 20.748 óbitos registrados nos documentos eclesiásticos. A mortalidade aumentou a partir de 1877 , chegando em 1878 a representar $67,3 \%$ do total de óbitos entre a população livre. Já entre os escravizados, a porcentagem de óbitos em 1878 foi de $31,4 \%$ e, entre os libertos, de $52,4 \%$. Em relação à condição jurídica, o número absoluto de escravizados e libertos não foi representativo se comparado ao volume total de óbitos. Durante o período, somente 290 indivíduos na condição de escravizados tiveram seus registros de óbitos realizados na Igreja; entre os libertos, contam-se 21 (tabela 1).

Tabela 1 - Óbitos por ano e condição jurídica, Freguesia de São José (Fortaleza), 1870-1879.

\begin{tabular}{cccccccc}
\hline & \multicolumn{3}{c}{ Absoluto } & \multicolumn{4}{c}{ \% em relação ao total de cada CJ } \\
Ano & Escravizado(a) & Liberto(a) & Livres & Total & Escravizado(a) & Liberto(a) & Livres \\
\hline 1870 & 32 & 4 & 364 & 400 & 11,0 & 19,0 & 1,78 \\
1871 & 23 & 1 & 324 & 348 & 7,93 & 4,76 & 1,59 \\
1872 & 12 & 2 & 707 & 721 & 4,14 & 9,52 & 3,46 \\
1873 & 18 & 1 & 652 & 671 & 6,21 & 4,76 & 3,19 \\
1874 & 27 & 1 & 588 & 616 & 9,31 & 4,76 & 2,88 \\
1875 & 20 & 0 & 770 & 790 & 6,90 & 0,00 & 3,77 \\
1876 & 16 & 1 & 628 & 645 & 5,52 & 4,76 & 3,07 \\
1877 & 16 & 0 & 2179 & 2195 & 5,52 & 0,00 & 10,7 \\
1878 & 91 & 11 & 13747 & 13849 & 31,4 & 52,4 & 67,3 \\
1879 & 35 & 0 & 478 & 513 & 12,1 & 0,00 & 2,34 \\
\hline Total & 290 & 21 & 20437 & 20748 & 100,0 & 100,0 & 100,0 \\
\hline
\end{tabular}

Fonte: Elaborado pela autora (2019). 
Entretanto, esse pequeno volume de óbitos de escravizados e libertos diz muito sobre o contexto de transformações econômicas e sociais que levou os médios e pequenos proprietários rurais a aderirem ao tráfico interprovincial de escravizados. Os indivíduos escravizados eram vendidos para as províncias do Sul e para a Amazônia, regiões onde a dinâmica econômica estava em expansão e, em razão da proibição do tráfico transatlântico de escravizados em 1850, dependiam do comércio interprovincial de escravizados (GRAHAM, 2002; MARTINS, 2012). Nesse contexto, o Ceará exportou milhares de escravizados para o sul. Durante a década de 1870 , enviou mais do que qualquer província brasileira, com exceção do Rio Grande do Sul, em termos proporcionais (GRAHAM, 2002).

Desta forma, o esvaziamento da população escravizada da província do Ceará por meio do tráfico interprovincial explica o baixo registro de óbitos de escravizados nos documentos eclesiásticos. Diante do reduzido volume de registro de óbitos de escravizados, optou-se pela análise do total de óbitos.

Os registros de óbitos, quando analisados por idade e sexo, permitem identificar os segmentos da população que mais sofriam com os impactos causados pelas condições sanitárias, doenças infecciosas e a seca, características do contexto de mortalidade, no período. Do ponto de vista demográfico, o século XIX faz parte do período denominado pré-transição demográfica e epidemiológica. No caso da população brasileira, como em outras populações tradicionais, o período de pré-transição é caracterizado por altas taxas de natalidade e de mortalidade ${ }^{11}$. Cabe considerar ainda que, em relação à mortalidade, predominavam os óbitos causados por doenças infecciosas ${ }^{12}$ (NOTESTEIN, 1945; OMRAN, 1971).

Em 1877 foi registrado um elevado número de óbitos de crianças de 1 a 4 anos de idade, seguido pelo de crianças menores de 1 ano. A concentração de óbitos nesses grupos etários sinaliza uma alta mortalidade infantil e na infância ${ }^{13}$. Tais resultados são evidências das condições de vida da

110 processo de transição demográfica inicia-se com o período pré-transição, marcado pela incidência de altas taxas de mortalidade e natalidade; seguido pela primeira fase, quando ocorre o início do declínio da mortalidade, mas com a natalidade ainda alta, o que acarreta o grande crescimento vegetativo da população; na segunda fase, além da queda da mortalidade também ocorre a queda da natalidade, consequentemente há baixo crescimento populacional; por fim, a terceira fase é aquela em que os níveis de natalidade e de mortalidade tendem a ser estabilizar e o crescimento populacional apresenta-se lento, nulo ou até negativo, a depender do ritmo da transição (NOTESTEIN, 1945).

12 Etapa que antecede a chamada teoria da transição epidemiológica, caracterizado pela mudança de um perfil de alta mortalidade por doenças infecciosas para outro perfil de predominância de óbitos por doenças cardiovasculares, neoplasias, causas externas e outras doenças crônico-degenerativas (OMRAN, 1971).

13 A Taxa de Mortalidade Infantil expressa o número de óbitos de menores de um ano de idade, por mil nascidos vivos. A taxa estima o risco de um nascido vivo morrer durante o seu primeiro ano de vida. Por sua vez, a Taxa de Mortalidade na Infância é a relação do número de óbitos de menores de 5 anos de idade por mil nascidos vivos. O indicador estima a probabilidade de um recém-nascido morrer antes de completar cinco anos de idade (RIPSA, 2008, p. 108). Nesta perspectiva, não é possível analisar a mortalidade infantil e/ou na infância sem a informação do denominador: os nascidos vivos. 
época, pois as crianças são as mais afetadas pelo péssimo estado sanitário do ambiente e pelo pouco acesso a serviços de saúde e alimentação adequada. Em relação à mortalidáde por sexo, não houve diferença significativa. É importante chamar a atenção para a pequena concentração de óbitos na idade jovem, adulta e, principalmente, na velhice. Tal resultado indica baixa expectativa de vida, pois a maioria dos adultos não chegam a idades mais avançadas (Gráfico 1).

\section{Gráfico 1 -Óbitos poridade e sexo, Freguesia de São José (Fortaleza), 1877.}

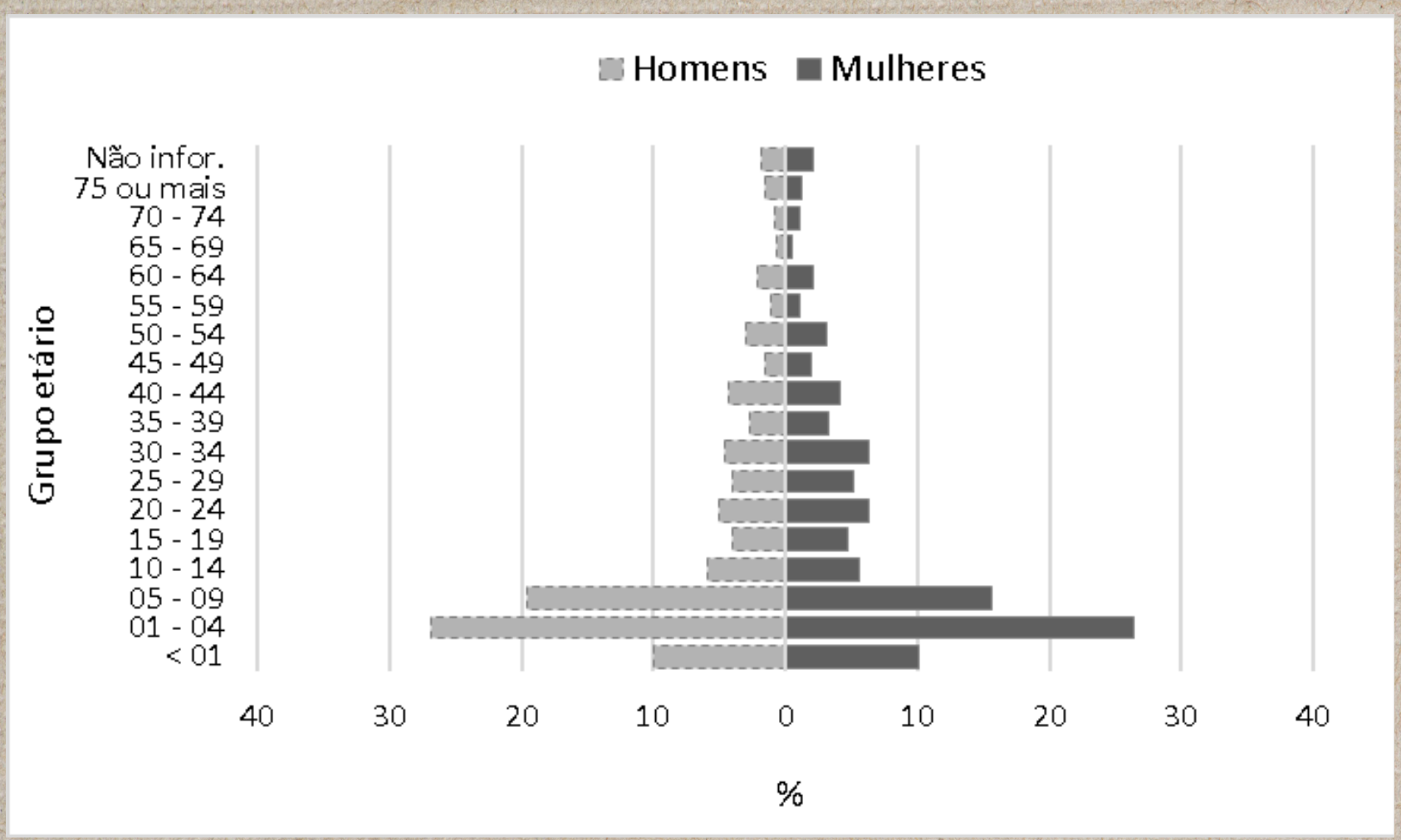

Fonte: Elaborado pela autora (2019).

Os fatores associados aos baixos níveis de saúde, desenvolvimento socioeconômico e condições de vida são agravados em 1878, ano auge da seca. Nesse ano, o volúme de óbitos cresceu de forma considerável. Na freguesia de São José, foi registrado um total de 13.849 óbitos. O crescimento foi de $500 \%$ em relação ao ano anterior. O aumento no número de óbitos na Capital do Ceará ocorreu, principalmente, devido a dois fatores: a migração massiva de retirantes refugiados da seca e a disseminação de doenças epidêmicas. Os mais afetados foram as crianças com idade entre 1 e 9 anos. Nos demais grupos etários, manteve-se um certo equilíbrio dos níveis de mortalidade entre os sexos. Neste caso, a mortalidade atingia tanto homens, quanto mulheres. Analisando o conjunto, pode-se afirmar que as vítimas fatais da seca foram crianças de 0 a 9 anos de idade. A mortalidade desses grupos etários representou 54,3\% (7.524 casos) em relação ao total de óbitos registrados no ano de 1878. O volume de óbitos entre idosos não se destaca, mas isso não significa que não foram atingidos pela seca. Apenas, conforme afirmado anteriormente, pode indicar que a expectativa de vida era tão baixa que muitos 
não conseguiam chegar a idades mais avançadas (Gráfico 2). Em geral, as crianças e os idosos são os mais atingidos em momentos de crise de mortalidade (LIVI-BACCI, 1984).

Gráfico 2-Óbitos poridade e sexo, Freguesia de São José (Fortaleza), 1878.

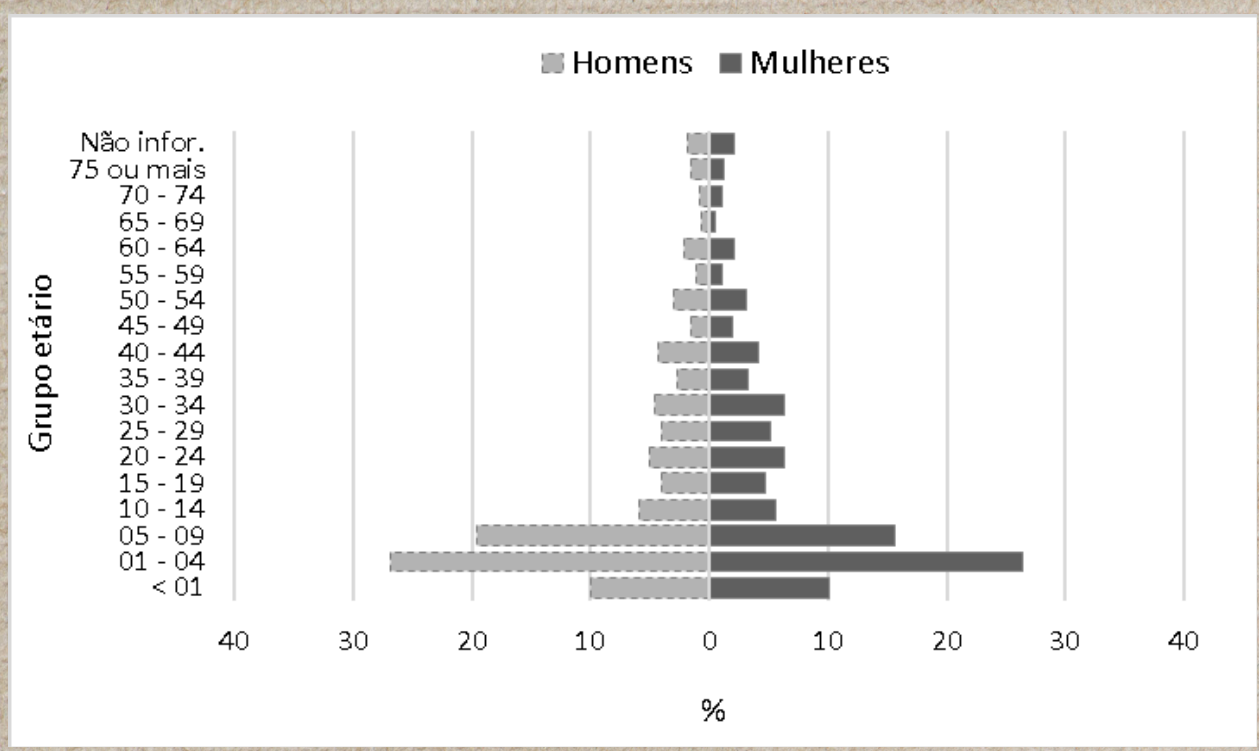

Fonte: Elaborado pela autora (2019).

Em 1879, o volume de óbitos decresceu em relação ao ano anterior. Houve a concentração de óbitos entre crianças menores de 1 ano, seguida de um aumento de mortalidade entre a população adulta, de 20 a 49 anos. Nesse ano, nota-se a grande quantidade de óbitos sem informação de idade. Em razão disto, desconfia-se da qualidade dos dados para esse ano, visto que a distribuição de óbitos por idade e sexo está muito diferente, se comparada aos anos anteriores. Dessa forma, não é possível uma análise confiável da distribuição da mortalidade por idade e sexo na freguesia de São José em 1879 (Gráfico 3).

Gráfico 3-Óbitos por idade e sexo, Freguesia de São José (Fortaleza), 1879.

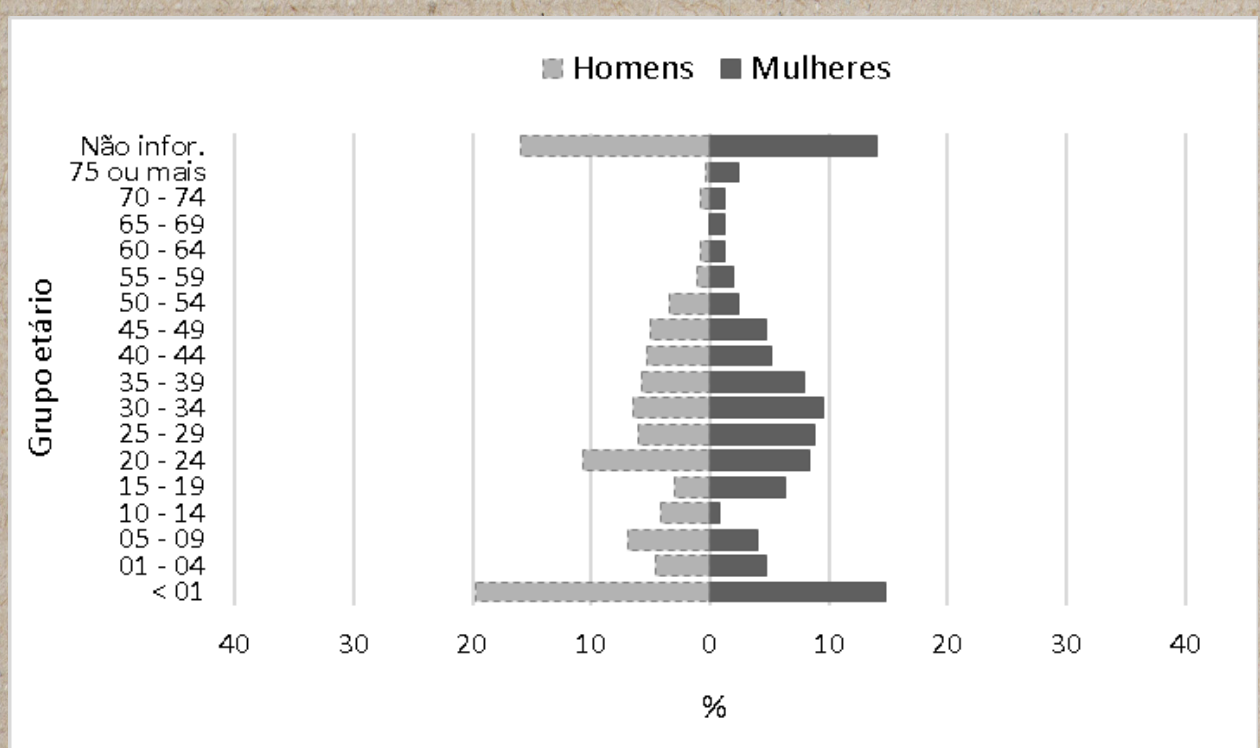

Fonte: Elaborada pela autora (2019). 
A análise da mortalidade por causas é um bom indicador para a compreensão das condições de vida e a identificação das doenças que mais atingiram a população no período da seca. Foram classificadas as seis principais causas de óbitos registrados na freguesia de São José, com base nos documentos eclesiásticos dos anos de 1877, 1878 e 1879 (Tabela 2).

Tabela 2 - Óbitos por seis principais causas de morte, Freguesia de São José (Fortaleza), 1877-1879.

\begin{tabular}{ccccccccc}
\hline \multicolumn{1}{c}{1877} & \multicolumn{1}{c}{1878} & & \multicolumn{1}{c}{1879} \\
\hline Doença & $\begin{array}{c}\text { Número } \\
\text { de óbitos }\end{array}$ & \% & Doença & $\begin{array}{c}\text { Número } \\
\text { de óbitos }\end{array}$ & $\%$ & Doença & $\begin{array}{c}\text { Número } \\
\text { de óbitos }\end{array}$ & $\%$ \\
\hline Febre amarela & 900 & 41,0 & Febre & 7.762 & 56,0 & Varíola & 79 & 15,4 \\
Espasmo & 360 & 16,4 & Febre amarela & 1.879 & 13,6 & Febre & 75 & 14,6 \\
Diarreia & 183 & 8,34 & Diarreia & 994 & 7,18 & Espasmo & 67 & 13,1 \\
Hidropisia/Anasarca & 102 & 4,65 & Espasmo & 416 & 3,00 & Inchação & 36 & 7,02 \\
Dentição & 49 & 2,23 & Varíola & 342 & 2,47 & Diarreia & 30 & 5,85 \\
Fome & 37 & 1,69 & Hidropisia/Anasarca & 260 & 1,88 & Beriberi & 22 & 4,29 \\
Não declarado & 26 & 1,18 & Não declarado & 124 & 0,90 & Não declarado & 15 & 2,92 \\
Outras & 538 & 24,5 & Outras & 2.072 & 15,0 & Outras & 189 & 36,8 \\
\hline Total & 2.195 & 100,0 & Total & 13.849 & 100,0 & Total & 513 & 100,0 \\
\hline
\end{tabular}

Fonte: Elaborada pela autora (2019).

Em 1877, as causas de morte mais registradas entre os falecidos na freguesia de São José, foram: febre amarela $(41,0 \%)$, espasmo $(16,4 \%)$, diarreia $(8,34 \%)$, hidropisia/anasarca $(4,65 \%)$, dentição $(2,23 \%)$ e fome (1,69\%). Em 1878, a febre se destaca como principal causa $(56,0 \%)$ dentre os óbitos registrados no ano (13.849), seguida de: febre amarela $(13,6 \%)$, diarreia (7,18\%), espasmo (3,00\%), varíola (2,47\%) e hidropisia/anasarca (1,88\%). Em 1879, as causas de óbito mais recorrentes foram: varíola $(15,4 \%)$, febre $(14,6 \%)$, espasmo $(13,1 \%)$, inchação $(7,02 \%)$, diarreia $(5,85 \%)$ e beribéri $(4,29 \%)$ (tabela 2$)$.

Tais resultados indicam que, para cada ano da seca, predominou uma doença específica como causa de morte, na forma de epidemias - definida como incidência, em curto período, de grande número de casos de uma doença (REZENDE, 1998). Em 1877, prevaleceu a febre amarela ${ }^{14}$; em 1878, a febre; e em 1879, a varíola.

Não podemos definir a febre como doença, na medida que é um sintoma marcado pelo aumento da temperatura corporal em consequência da resposta do organismo a invasores, normalmente, vírus e bactérias. No entanto, a presença de vírus e bactérias no organismo, pode ser sinal de alguma doença infecciosa. Neste período, Chernoviz classifica a existência de variados tipos de febres no Brasil: "adynamica, algida, amarela, ataxica, beliosa, catarrhal, cerebral, colliquativa, escarlatina, gastrica, hectica, inflammatoria, intermittente perniciosa, febre do

14 Além do aumento da temperatura do corpo, a febre amarela é caracterizada pela cor amarelada da pele e pelos vômitos pretos, aspectos dos quais deriva o nome da doença (CHERNOVIZ, 1890, p. 1087). 
leite ou lactea, febre lenta, colliquativa ou hectica, febre maligna, miliar, mucosa, puerperal, putrida, remittente, typhoide, urticaria" (CHERNOVIZ, 1890, p. 1087-1102).

Em relação à varíola, segundo Teófilo, a doença apareceu em Fortaleza em setembro de 1878 e durou até maio de 1879 , produzindo um total de 27.376 vítimas. As fontes utilizadas pelo autor foram os registros paroquiais de óbitos, de acordo um uma nota referente aos óbitos de dezembro de 1878: "N'esta cifra só estão comprehendidos os enterramentos feitos officialmente nos cemiterios de S. João Batista e Lagôa-Funda" (TEÓFILO, 1922, p. 243). Porém, entre os óbitos registrados na freguesia de São José a que tivemos acesso, a maioria dos indivíduos foram sepultados no cemitério São João Batista, embora também apareça o cemitério de Lagoa Funda, em menor quantidade de casos, em 1879. Desta forma, provavelmente os dados informados por Teófilo não são confiáveis, ou é possível que a mortalidade ocasionada pela varíola seja bem superior à registrada pela nossa fonte de dados.

No que se refere às demais causas de morte, o espasmo, segundo Bluteau $(1728$, p. 547) é o "mesmo que convulsão ou retração. Uma convulsão involuntária dos nervos". O dicionário de medicina popular de autoria de Chernoviz (1890, p. 1028) define:

ESPASMO. Contraç̧ão involuntaria dos musculos, principalmente dos que não obedecem á vontade, taes são os do estomago, dos intestinos, da urethra, etc. Precede frequentemente a convulsão, mas pode tambem existir sem ella. Além d'isto, o sentido da palavra espasmo é mui vago: ás vezes emprega-se como synonymo de convulsão; frequentemente toma-se por ataque de nervos. Applica-se tambem o nome ar de espasmo á molestia chamada tetano; e com o mesmo nome se designa algumas vezes a apoplexia. Pelo que se vê, não posso indicar n'este logar o tratamento do espasmo.

O próprio Chernoviz afirma que não é possível prescrever tratamento para o espasmo, porque a palavra é muito ampla, neste caso, pode representar diversas doenças ou sintomas, tais como: convulsão, ataque dos nervos, tétano ou apoplexia. Diante disso, sentimos a necessidade de cruzar essa causa com as informações de idade. Os resultados indicaram que de 1877 a 1879, dentre os 843 óbitos ocasionados pelo espasmo, 80,3\% (677 óbitos) ocorreu entre crianças menores de 1 ano de idade ${ }^{15}$. Desta forma, assumimos que a causa "espasmo" presente nos registros paroquiais da paróquia de São José tem o sentido de convulsão. Segundo o autor, as convulsões aparecem principalmente quando os primeiros dentes das crianças começam a nascer, sendo os principais sintomas: "febre, insomnia, medo, pelle secca, prisão do ventre, as crianças gritam, choram muito, e mudam continuadamente de côr" (CHERNOVIZ, 1890, p. 1262).

$1514,2 \%$ (120) dos registros com a causa espasmo foi entre crianças de 1 a 4 anos; $1,7 \%$ (14) entre 5 a 9 anos; $0,4 \%$ (3) entre 20 a 24 anos; $0,2 \%$ (2) entre 35 a 44 anos; 0,1\% (1) entre 55 a 59 anos; e 3,1\% (26) dos registros de óbitos com a causa espasmo não tiveram a idade declarada. 
A diarreia apareceu nos registros paroquiais como: "diarrea", "diarrhea", "disenteria", "camaras" ou "caimbras de sangue", como era popularmente conhecida. Bluteau define como "doença, fluxo de ventre em que sai dele evacuação frequente de matéria clara, água, mucosa, glutinosa, com espuma, biliosa, ou denegridados intestinos, talvez com puxos" (BLUTEAU, 1728, p. 436). O sintoma principal é a "frequência e a fluidez das dejecções alvinas" (CHERNOVIZ, 1890, p. 864). A diarreia é um sintoma marcado por complicações, geralmente provocadas por: intoxicação alimentar, causada pela ingestão de alimentos contaminados; consumo de água contaminada; ou, ainda, sinal de gastroenterite ou infecção intestinal. Um sintoma muito comum em períodos de seca, pela ingestão de água e alimentos contaminados.

A hidropisia, também chamada anasarca, é definida como "inchação geral ou muito extensa do corpo, produzida pela accumulação no tecido cellular subcutâneo. Chamam-lhe tambem hydropisia do tecido cellular" (CHERNOVIZ, 1890, p. 151). No que se refere à dentição, trata-se de uma causa relacionada ao crescimento dos primeiros dentes de uma criança. É um processo natural, contudo quando ocorrem complicações propicia grande mortalidade no primeiro ano de vida. As complicações são determinadas por vômitos, diarreias, convulsões e inchação dolorosa das gengivas, geralmente, acompanhados de febre (CHERNOVIZ, 1890, p. 804). Por sua vez, o beribéri é uma doença causada pela deficiência da vitamina B1 no organismo. É definida como "fraqueza geral, inchação do corpo, paralysia; e terminando, nos casos fataes, por suffocação, asphyxia ou extenuação das forças" (CHERNOVIZ, 1890, p. 314). E por fim, a fome, decorrente da falta de alimentos.

Neste sentido, as causas de óbitos apresentadas condizem com o contexto de mortalidade fortemente influenciado pela seca e pelas doenças epidêmicas infecciosas, como a febre amarela, febre e a varíola. Outras causas se destacaram como resultado do estado sanitário precário do ambiente, da ingestão de água e alimentos contaminados, como a diarreia; e dá carência alimentar de certos nutrientes, como o beribéri.

A alta mortalidade registrada em Fortaleza no período da seca foi, primordialmente, em virtude do deslocamento massivo de retirantes vindos do interior da província em direção à Capital. Com base nas informações de naturalidade, entre os óbitos registrados nos documentos eclesiásticos, analisam-se os principais locais de origem desses retirantes. No entanto, a qualidade dessas informações variou conforme os anos. Em 1877, 96,5\% dos registros não apresentaram informações sobre naturalidade, por sua vez, em 1878 somente $26,3 \%$ dos registros não tiveram a informação declarada, o que possibilita uma análise sobre o local de origem dos que vieram a falecer na Capital, no auge da seca (tabela 3). 
Tabela 3 -Óbitos por principais locais de naturalidade, Freguesia de São José (Fortaleza), 1877-1879.

\begin{tabular}{|c|c|c|c|c|c|c|c|c|}
\hline \multicolumn{3}{|c|}{1877} & \multicolumn{3}{|c|}{1878} & \multicolumn{3}{|c|}{1879} \\
\hline Naturalidade & $\begin{array}{l}\text { Número } \\
\text { de óbitos }\end{array}$ & $\%$ & Naturalidade & $\begin{array}{c}\text { Número de } \\
\text { óbitos }\end{array}$ & $\%$ & Naturalidade & $\begin{array}{l}\text { Número } \\
\text { de óbitos }\end{array}$ & $\%$ \\
\hline Não de clarado & 2103 & 95,8 & Não declarado & 3646 & 26,3 & Não declarado & 134 & 26,1 \\
\hline Fortaleza/CE & 22 & 1,00 & Baturité/CE & 1325 & 9,57 & Fortaleza/CE & 171 & 33,3 \\
\hline Ceará & 10 & 0,46 & Fortaleza/CE & 949 & 6,85 & Aracaty $/ \mathrm{CE}$ & 24 & 4,68 \\
\hline Aracaty $/ \mathrm{CE}$ & 4 & 0,18 & Telha/CE & 482 & 3,48 & Baturité/CE & 17 & 3,31 \\
\hline Rio Grande do Norte & 4 & 0,18 & Quixeramobim/CE & 419 & 3,03 & Quixeramobim/CE & 12 & 2,34 \\
\hline Quixeramobim/CE & 3 & 0,14 & Pereiro/CE & 416 & 3,00 & Icó/CE & 9 & 1,75 \\
\hline Crato $/ \mathrm{CE}$ & 3 & 0,14 & Canindé/CE & 415 & 3,00 & Telha/CE & 8 & 1,56 \\
\hline Maranguape/CE & 3 & 0,14 & Aquiráz/CE & 320 & 2,31 & Aquiraz & 6 & 1,17 \\
\hline Baturité/CE & 3 & 0,14 & Cascavel/CE & 300 & 2,17 & Crato & 6 & 1,17 \\
\hline Pereiro/CE & 3 & 0,14 & São Francisco/CE & 298 & 2,15 & Lavras & 6 & 1,17 \\
\hline Aquiraz/CE & 2 & 0,09 & Lavras/CE & 270 & 1,95 & Maranguape & 6 & 1,17 \\
\hline Outros & 35 & 1,59 & Outros & 5009 & 36,2 & Outros & 114 & 22,2 \\
\hline Total & 2.195 & 100 & & 13.849 & 100,0 & & 513 & 100,0 \\
\hline
\end{tabular}

No ano de 1878, dentre os 13.849 óbitos registrados na freguesia de São José em 1878, 9,6\% (1.325 casos) são de indivíduos naturais da vila de Baturité. A vila é relativamente próxima de Fortaleza, localizada a $115 \mathrm{~km}$ de distância. O segundo local de naturalidade mais recorrente entre as pessoas que faleceram foi a própria cidade de Fortaleza, ao representar somente 6,9\% (949 casos) em relação ao total de óbitos (tabela 3). Nesse sentido, pode-se afirmar que a população residente em Fortaleza, embora também tenha sido afetada pela alta mortalidade, teve um peso muito pequeno em relação ao total de óbitos.

A distribuição dessas localidades por meio de um mapa permite visualizar as regiões da província dos retirantes que vieram a falecer na freguesia de São José. É importante destacar que o mapa utilizado é de recorte geográfico atual, mas foi realizada uma pesquisa em mapas da época para identificar os locais de naturalidade informados. Telha (hoje denominada Iguatu), região do sertão cearense, a 380 $\mathrm{km}$ da Capital, foi o terceiro local de naturalidade mais frequente nos registros de óbitos. Embora a sua representação em relação ao todo seja pequena, aproximadamente 3,5\% (482 casos), se somada com as vilas de Pereiro $(3,0 \%)$ e Lavras $(1,9 \%)$ que também faziam parte da mesma região de sertão, no sul da província, representa 8,4\% em relação aos óbitos totais. Chama atenção a distância dessas localidades em relação a Fortaleza, aproximadamente $400 \mathrm{~km}$ (Mapa 1). Esses dados reforçam o relato de que diariamente partiam de todos os pontos da província caravanas de pessoas à procura da "terra prometida", idealizada na cidade de Fortaleza (TEÓFILO, 1922, p. 97).

Quixeramobim foi o quarto local de naturalidade mais frequente nos registros de óbitos. Junto com Canindé, era parte da região central do sertão cearense. Representaram $6,0 \%$ em relação ao total de óbitos: São Aquiraz e Cascavel são regiões mais próximas de Fortaleza, localizadas ao redor da cidade 
a um raio de aproximadamente $80 \mathrm{~km}$. Juntas representaram $4,5 \%$ em relação ao total de óbitos. Por fim, São Francisco, uma região de serra, localizada no norte cearense, a cerca de $115 \mathrm{~km}$ de distância da Capital, representou em 1878, 2,2\% entre os óbitos por locais de naturalidade (mapa 1).

\section{Mapa 1 - Óbitos por dez principais locais de naturalidade, Freguesia de São José (Fortaleza), 1878.}

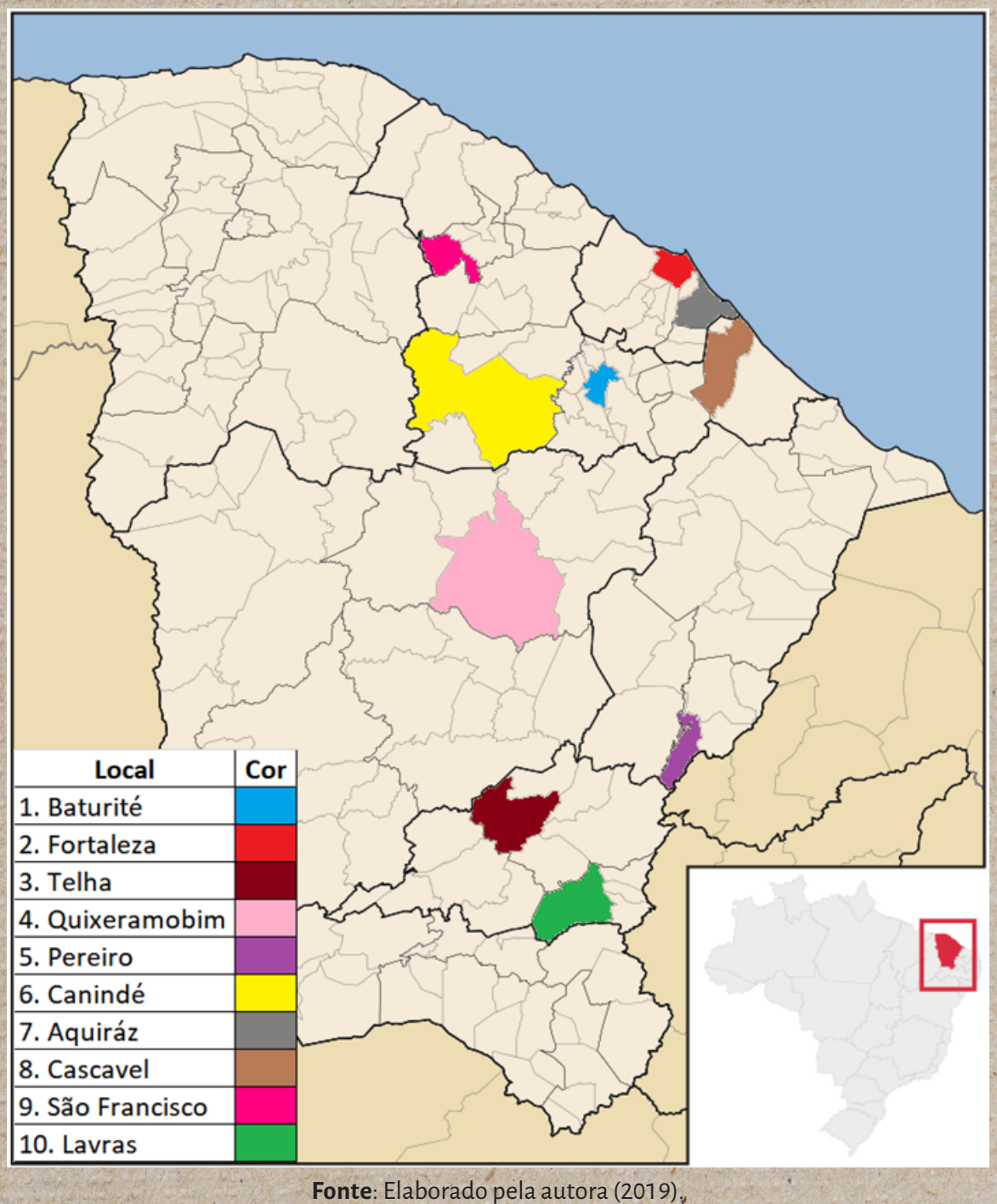

Diante disso, a alta mortalidade registrada em Fortaleza em 1878 foi primordialmente em virtude do deslocamento massivo de retirantes vindos do interior em direção à Capital. Os resultados indicam que a grande massa de retirantes em Fortaleza não veio de uma cidade específica e sim de várias localidades, que contribuíram - umas de forma mais intensa do que outras - para a sobrepopulação da Capital. Neste cenário, a freguesia de São José recebeu imigrantes a um raio de aproximadamente $150 \mathrm{~km}$ ao redor da cidade e de localidades da região CentroSul do sertão cearense, por volta de $400 \mathrm{~km}$ de distância da cidade.

Em 1879 o volume de óbitos decresceu e, segundo as informações de naturalidade, pode-se afirmar que a presença de imigrantes na freguesia diminuiu em relação ao ano anterior. $40,7 \%$ 
dos óbitos registrados em 1879 eram de indivíduos naturais de outras localidades da província do Ceará. $26,1 \%$ dos óbitos registrados não tiveram a informação de naturalidade declarada, e $33,3 \%$ eram naturais da própria cidade de Fortaleza (tabela 3).

\section{Considerações finais}

Pode-se concluir que este exercício de análise dos registros paroquiais de óbitos possibilitou a ampliação do conhecimento sobre o contexto de mortalidade e migração interna em Fortaleza, durante a seca ocorrida entre 1877 e 1879. Realizamos uma análise da estrutura de óbitos por idade e sexo, assim como apresentamos também dados sobre as principais causas de óbitos e os locais de naturalidade.

Os grupos etários mais atingidos pela seca foram as crianças de 0 a 9 anos de idade. A alta mortalidade entre crianças indica, de maneira geral, baixos níveis de saúde, desenvolvimento socioeconômico e condições de vida. Em relação à pequena concentração de óbitos em idades mais avançadas, revela baixa expectativa de vida, geralmente, em virtude do não acesso aos serviços de saúde, má alimentação, habitação em locais precários e péssimo estado sanitário, dentre outros fatores.

Entre as causas que mais predominaram estão: a febre, a febre amarela e a diarreia. Tal constatação reforçou a ideia de que, durante o período de seca, agravou-se a disseminação de doenças epidêmicas infecciosas, elevando os níveis de mortalidade. Mas esse aumento da mortalidade foi, sobretudo, consequência da imigração massiva de indivíduos que saíram do interior da província e se dirigiram a Fortaleza, em busca de auxílio público. Entre os locais de naturalidade, nenhum predominou de forma significativa, mas é possível afirmar que Fortaleza recebeu imigrantes de cidades vizinhas e de localidades no sertão do Centro-Sul cearense. Nesta perspectivá, este artigo procurou contribuir para alargar o conhecimento histórico sobre o tema da seca no Nordeste, das migrações, da mortalidade e das doenças na cidade de Fortaleza nas últimas décadas do século XIX.

\section{Referências}

AGUIAR, João José Ferreira de. [Relatório] 22 fev. 1878, passou a administração da província do Ceará ao Exmo. Sr. Dr. Paulino Nogueira Borges da Fonseca. Fortaleza: Typographia Brasileira, 1878. Disponível em: <http://ddsnext.crl.edu/titles>. Acesso em: 15 jul. 2019. 
BARBOSA, Francisco Carlos ]. Administrar a precariedade: Saúde Pública e epidemias em Fortaleza (18501880). O público o privado, Fortaleza, v.7, n.13, p.95-106, jan./jun. 2009. Disponível em: <http://www.uece.br/ mahis/dmdocuments/carlosjacinto.pdf>. Acesso em: 20 abr. 2019.

BARROS, José ]ulio de Albuquerque. [Discurso] 1 nov. 1878 , falla com que abriu a $1^{\text {a }}$ sessão da $24^{\mathrm{a}}$ legislatura' da Assembléa Provincial. Fortaleza: Typographia Brasileira, 1879. Disponível em: <http://ddsnext.crl.edu/ titles>. Acesso em: 15 jul. 2019.

BLUTEAU, Raphael. Vocabulario portuguez \& latino: aulico, anatomico, architectonico. Coimbra: Collegio das Artes da Companhia de Jesus, 1712-1728. v. 8. Disponível em: <http://dicionarios.bbm.usp.br/pt-br/ dicionario/edicao/1>. Acesso em: 2 ago. 2019.

BURKE, Peter. Abertura: a nova história, seu passado e seu futuro. In: BURKE, Peter (Org.). A escrita da História: novas perspectivas. São Paulo: Editora Unesp, 2011. p. 7-38.

CARDOSO, Antonio Alexandre I. As secas e as migrações entre o Ceará e o território amazônico (18451877). Revista Espacialidades, Natal, v. 7, n. 1, p. 34-46, maio 2014. Disponível em: <https://periodicos.ufrn.br/ espacialidades/article/view/17621/11482>. Acesso em: 28 jul. 2019.

CHALHOUB, Sidney. Cidade febril. Cortiços e epidemias na Corte imperial. São Paulo: Companhia das Letras, 1996.

CHERNOVIZ, Pedro Luiz Napoleão. Diccionario de Medicina Popular e das sciencias accessarios para o uso das famílias. 6 ed. Paris: A. Roger \& F. Chernoviz, 1890. v. 1. Disponível em: <http://dicionarios.bbm.usp.br/pt-br/ dicionario/edicao/1>. Acesso em: 2 ago. 2019.

COSTA, Jurandir Freire. Ordem médica e norma familiar. Rio de Janeiro: Graal. 1979.

GIRÃO, Raimundo. História econômica do Ceará. Fortaleza: Instituto do Ceará, 1947.

GRAHAM, Richard. Nos tumbeiros mais uma vez? O comércio interprovincial de escravos no Brasil. Revista Afro-Ásia, Salvador, v. 27, p. 121-160, 2002.

ICREJA CATÓLICA. Registros paroquiais, 1726-1952. São José da Catedral (Centro, Fortaleza, Ceará). Óbitos $1862-$ 1873, 1872-1882, 1873-1880, 1878-1889. Microfilme 2124304, n. filme 004815740, itens 2-12, imagem 4442840. Disponível em:<https://www.familysearch.org/search/film/004815740>. Acesso em: 25 mar. 2019.

JORGE, Karina Camarneiro. A modificação da vida urbana da cidade de São Paulo no século XIX a partir das ações sanitárias - A construção de cemitérios e a prática de sepultamentos. In: ENCONTRO NACIONAL DE HISTÓRIA, 24., 2007, São Leopoldo. Anais... Rio Grande do Sul: ANPUH, 2007, p. 1-9.

LIVI-BACCI, Massimo. Crises de mortalidade: definição, métodos de cálculo, análise das consequências. In: MARCÍLIO, Maria Luiza (Org.). População e sociedade. Evolução das sociedades pré-industriais. Petrópolis: Vozes, 1984.p. 69-109.

MARCÍLIO, Maria Luiza. Os registros paroquiais e a História do Brasil. Varia História, Belo Horizonte, v. 20 , n. 31, p. 13-20, 2004.

MARCÍlIO, Maria Luiza. Sistemas demográficos no Brasil do século XIX. População e sociedade: Evolução das sociedádes pré-industriais. Petrópolis: Vozes, 1984. 
MARTINS, Letícia Lustosa. Variola em Fortaleza: marcas profundas de uma experiência dolorosa (1877-1881). 2012.153 f. Dissertação (Mestrado em História)-UECE, Fortaleza, 2012.

MELO, Evaldo Cabral de. Onorte agrárioe o Império. Rio de Janeiro: Nova Fronteira, 1984.

NOTESTEIN, Frank W. Population: the long view. In: SCHULTZ, Theodore W. (Org.). Food for the world. Chicago: University of Chicago Press, 1945. p. 36-47.

NOZOE, Nelson; BASSANEZI, Maria Silvia; SAMARA, Eni de M. Osrefugiados da seca: emigrantes ceareses, 18881889. Campinas: NEHD; NEPO; CEDHAL, 2003.

OMRAN, Abdel R. The epidemiologic transition: a theory of the epidemiology of population change. The MilbankMemorial Fund Quarterly, New York, v. 49, n. 4, part1, p. 509-538, out. 1971.

PONTE, Sebastião Rogério. Fortaleza Belle Époque. Reformas urbanas e controle social (1860-1930). 2. ed. Fortaleza: Fundação Demócrito Rocha, 1999.

PORTER, Roy. História do corpo. In: BURKE, Peter (Org.). A escrita da História: novas perspectivas. São Paulo: Editora da Unesp, 2011. p. 297-333.

REZENDE, Joffre Marcondes. Epidemia, endemia, pandemia. Epidemiologia. Revista de Patologia Tropical, Cooiás, v. 27, n. 1, p. 153-155, 1998.

ROCHA POMBO, José Francisco de. História do Rio Grande do Norte. Rio de Janeiro: Annuario do Brasil, 1922.

RIPSA, Rede Interagencial de Informação para a Saúde. Indicadores básicos para a saúde no Brasil: conceitos e aplicações. 2 ed. Brasília: Organização Pan-Americana de Saúde, 2008. Disponível em: <http://tabnet.datasus. gov.br/tabdata/livroidb/2ed/indicadores.pdf $>$. Acesso em: 10 set. 2019.

SECRETO, María Verónica. Ceará, a fábrica de trabalhadores: emigração subșidiada no final do século XIX. Trajetos Revista de História UFC, Fortaleza, v. 2, n. 4, p. 47-65, 2003.

SOUZA, JoséWeyne Freitas. Secas e socorros públicos no Ceará: doença, pobreza e violência (1877-1932). Projeto História, São Paulo, n. 52, p. 178-219, jan./abr. 2015.

TEÓFILO, Rodölfo. História da seca no Ceará (1877-7880), Rio de Janeiro: Imprensa Inglesa, 1922.

VIEIRA JUNIOR, Antônio Otaviano. O açoite da seca: família e migração no Ceará (1780-1850). In: ENCONTRO NACIONAL DE ESTUDOS POPULACIONAIS, 13., 2002, Ouro Preto/MG. Anais... Ouro Preto/MC: ABEP, 2002. p. 1-16.

WITTER, Nikelen Acosta. Males e epidemias: sofredores, governadores e curadores no sul do Brasil (Rio Grande do Sul, século XIX). 2007.292 f. Tese (Doutorado em História)-UFF. Niterói, 2007.

Recebido em: 3 de setembro de 2019 Aprovado em: 6 de dezembro de 2019 